Eur. J. Clin. Chem. Clin. Biochem.

Vol. 31, 1993, pp. 559-565

(C) 1993 Walter de Gruyter \& Co.

Berlin - New York

\title{
Oxalate in the Human Thyroid Gland
}

\author{
By R. Wahl, Regine Fuchs and E. Kallee \\ Medizinische Klinik und Poliklinik, Abteilung IV, Eberhard-Karls-Universität Tübingen
}

(Received February 8/June 10, 1993)

\begin{abstract}
Summary: Ninety-seven fixed surgical thyroid specimens and 63 unfixed and 40 fixed thyroid specimens from autopsies were examined for their oxalate content. Proteases were used to process the tissue, and the oxalate was determined with an enzymatic assay. The fixed samples were grouped into seven diagnostic categories (diffuse colloid goitre; partially diffuse, partially nodular colloid goitre; nodular colloid goitre; goitre with multifocal functional autonomy; non-functioning adenoma; unifocal functional autonomy; Graves' disease). The oxalate concentrations of the samples were mainly dependent on age and gender, which were distributed unequally among the seven diagnostic groups. In thyroid tissue from cases of Graves' disease, however, the concentration of oxalate was remarkably low and statistically different from those of four of the six other groups.
\end{abstract}

\section{Introduction}

Dietary intake contributes only a minor proportion of the oxalate in humans. More than $80 \%$ of oxalate is derived from metabolism, in particular of glycine and ascorbic acid (1). A small amount is also synthesized from glycolic acid, hydroxyproline, tryptophan (2), and possibly also from purines (3). The intestinal flora may also play a role (4).

Microscopic and macroscopic calcium oxalate crystals are deposited in organs such as the kidneys, thymus, vessel walls, the prostate, testicles, brain, eyes, and in granulation tissue $(5-15)$. Calcium oxalate exists in three hydration states in the organism: monohydrate (whewellite), dihydrate (weddellite) and trihydrate, the monohydrate being the least soluble (16). As a rule, the calcium oxalate deposits are only found in injured tissue or in pathological states (17).

Calcium oxalate deposits in the colloid of thyroid follicles were first discovered by Krause in 1868 (18); using X-ray diffraction, Richter \& McCarty (8) identified this calcium oxalate as the monohydrate. According to MacMahon et al. (17) the distribution of calcium oxalate crystals in the thyroid is not homogenous. Prolonged storage of bulk thyroid tissue in either acid formaldehyde (for two weeks) or in buf- fered formaldehyde (over six months) has no obvious effect on the number of oxalate crystals, i. e., crystals are not lost during this fixation in contrast to other fixation methods $(19,20)$.

Previous morphological studies have documented that oxalate can be found in crystal form in the thyroid. The current work seeks to establish a system for quantifying the amount of oxalate present, and to correlate this with morphological and functional quantities by using histological and scintigraphical methods. To the authors' knowledge, there have been no data published to date on this subject. The results of this study might be used as a basis for further research on the pathophysiological properties of oxalate.

\section{Materials and Methods}

Ninety-seven surgical specimens fixed in $4 \%$ formaldehyde were examined. The thyroid tissue came from the Tübingen-Stuttgart area in Southern Germany, where goitres are endemic.

The diagnostic categories used are based upon histological findings which do not entirely correspond to WHO nomenclature. Any remarkable scintigraphic findings were also taken into account, especially since hot nodules cannot be easily identified histologically. Histologically and scintigraphically 
'normal' thyroids were not available for this study. Treatment of patients was ignored because thyroid diseases have in general a long history.

Classification of diagnostic groups:

1. Diffuse colloid goitre

2. partially diffuse, partially nodular colloid goitre

3. Nodular colloid goitre

4. Goitre with multifocal functional autonomy (based on histological findings)

\section{Non-functioning adenoma (cold nodule)}

6. Unifocal functional autonomy (hot nodule)

\section{Graves' disease}

Tissue specimens were processed within one month after their receipt. Unfixed thyroid glands were stored at $-20^{\circ} \mathrm{C}$, and then thawed for further processing. Unfixed as well as fixed glands were ground in an electric blender. The tissue was then placed in plastic bags and flattened manually, frozen at $-20^{\circ} \mathrm{C}$, then crushed into small pieces with a hammer. These were subsequently. pulverized with a mortar and pestle in liquid nitrogen. About $5 \mathrm{~g}$ of this material were used for further processing. The quantity of oxalate was measured with an enzymatic test system (Sigma Diagnostics, Deisenhofen, Germany, catalog No. 590).

Two separate pilot measurements showed that formaldehyde concentrations as applied to the fixation of tissue clearly inhibited the enzymatic oxalate determination, whereas in the concentration range of about $50 \mathrm{mg} / \mathrm{l}$ or lower formaldehyde did not interfere. Formaldehyde was therefore removed from the tissue preparation before analysis, using a method that did not also remove oxalate. Calcium chloride was chosen for this purpose, because calcium forms insoluble calcium oxalate complexes with free oxalate ions. The calcium chloride was dissolved in $99.9 \%$ ethanol rather than in water in order to lower the solubility product of these complexes. When calcium chloride was dissolved only in water instead of ethanol no precipitates of calcium oxalate were recognizable.

The tissue specimens were washed twice with $2.5 \mathrm{~g} / \mathrm{l}$ and twice with $5 \mathrm{~g} / 1 \mathrm{CaCl}_{2}$ in ethanol, each time for two hours. Between each washing, the samples were centrifuged at approximately $100 \mathrm{~g}$ for 10 minutes and the supernatants discarded. The alcohol residues were removed by heating the test tubes at $60-$ $70^{\circ} \mathrm{C}$ until dry. Oxalate does not decompose at this temperature. In a pilot measurement the analytical recovery of pure oxalic acid $(100 \mathrm{mg} / \mathrm{l})$, dissolved in $4 \%$ formaldehyde and precipitated with $\mathrm{CaCl}_{2}$-ethanol in the same manner as described above, ranged from $92-98 \%$. The mean recovery was $94 \%(n=6)$. Oxalic acid loss in the supernatant was therefore tolerably constant, small and considered negligible. The Merckoquant $^{(i)}$ formaldehyde test (Merck; Darmstadt, Germany; measuring range $10-100 \mathrm{mg} / \mathrm{l}$ ) did not detect any formaldehyde after the fourth washing, and the Aquamerck ${ }^{\circledR}$ formaldehyde test (Merck, Darmstadt, Germany; measuring range 0.1-1.5 $\mathrm{mg} / \mathrm{l})$ only detected $0.15 \pm 0.44 \mathrm{mg} / \mathrm{l}(\mathrm{n}=12)$.

The alcohol treatment dehydrated the thyroid tissue. This allowed the omission of a lyophilization procedure, which would otherwise have been required. The next step was the precise weighing of the dry thyroid material.

The enzymatic oxalate test used was originally designed for the measurement of oxalate in urine. Consequently, the thyroid specimens had to be submitted to special preparation procedures. According to Andrews et al. (21) fat can interfere in the determination of oxalate. The pulverized and dried tissue specimens were therefore treated with pure light petroleum (b. p. $40-60^{\circ} \mathrm{C}$, Merck, Darmstadt, Germany), in which oxalate is insoluble, in order to remove any fat remaining after the alcohol treatment. The test tubes containing the tissue powder with the light petroleum were briefly submitted to a vacuum, which was then released to accomplish tissue saturation. The light petroleum with any dissolved fat was discarded and the residues were evaporated.

The enzymatic assay for the determination of oxalate must be performed at an acidic $\mathrm{pH}$. This acid environment causes on the one hand the dissolution of the calcium oxalate crystals, but on the other hand, free oxalate binds to protein under the acidic conditions. Moreover, protein would partially precipitate in an acid environment. In order to digest the proteins already denatured by formaldehyde and alcohol, the tissue specimens were therefore treated with proteolytic enzymes (22) prior to adding the acid. Five different proteases as well as two nucleases were used each in a volume of $3 \mathrm{ml}$.

1. Dispase [EC 3.4.24.4] $\left.]^{1}\right)\left(5 \mathrm{~g} / 1 \mathrm{H}_{2} \mathrm{O}\right.$; incubation $\left.16 \mathrm{~h}, 37^{\circ} \mathrm{C}\right)$

2. Pepsin [EC 3.4.23.1] $\left.]^{1}\right)(2 \mathrm{~g} / 10.06 \mathrm{~mol} / 1 \mathrm{HCl}$; incubation $8 \mathrm{~h}$, $25^{\circ} \mathrm{C}$ )

3. Trypsin [EC 3.4 .21 .4$](2 \mathrm{~g} / 10.001 \mathrm{~mol} / 1 \mathrm{HCl}$; incubation $8 \mathrm{~h}$, $25^{\circ} \mathrm{C}$ )

4. Papain [EC 3.4.22.2] $)(2 \mathrm{~g} / \mathrm{l} 0.05 \mathrm{~mol} / \mathrm{l}$ phosphate buffered saline; incubation $16 \mathrm{~h}, 40^{\circ} \mathrm{C}$ )

5. Pronase E [EC 3.4.24.4 $\left.]^{1}\right)(3 \mathrm{~g} / 10.067 \mathrm{~mol} / 1$ phosphate buffered saline; incubation $16 \mathrm{~h}, 40^{\circ} \mathrm{C}$ )

6. DNase and RNase $\left.{ }^{1}\right)\left(0.003 \mathrm{~g} / 1 \mathrm{H}_{2} \mathrm{O}\right.$ and $0.1 \mathrm{~g} / 1 \mathrm{H}_{2} \mathrm{O}$; incubation $8 \mathrm{~h}, 25^{\circ} \mathrm{C}$ )

The dispase (cat. No. 165859) and pepsin (porcine, cat. Nr. 108057) were from Boehringer, Mannheim, Germany, trypsin (bovine, cat. No. 24579), papain (cat. No. 7144), pronase E (cat. No. 7433), bovine DNase (cat. No. 16326) and bovine RNase (cat. No. 24686) were supplied by Merck, Darmstadt, Germany.

To each litre of protease solution $4 \mathrm{ml}$ of a streptomycinpenicillin concentrate ( $500000 \mathrm{U} / 0.5 \mathrm{~g}$ in $20 \mathrm{ml}$; Eurobio, Paris, France) and $1 \mathrm{~g}$ potassium sorbate were added as preservatives. Between each proteolytic treatment, the samples were centrifuged at $1600 \mathrm{~g}$ for 30 minutes and the supernatant was discarded. Oxalate was determined in the protease and nuclease supernatants of a number of samples. Any protease residue remaining in the tissue sediment was inactivated by heating the samples for 15 minutes at $90^{\circ} \mathrm{C}$ to avoid interference with the enzymatic test system. The Albym ${ }^{\otimes}$ dipstick test (Boehringer, Mannheim, Germany; practical sensitivity limit $60 \mathrm{mg} / \mathrm{l}$ ), designed for the detection of urinary protein, confirmed that there were no tissue protein residues left in the samples. The residues of the protease proteins were not detected by this dipstick method, but they were detectable by Coomassie-Brilliant-Blue methods for protein determination. The sediment of thyroid tissue was subsequently acidified with $2 \mathrm{ml} 2 \mathrm{~mol} / 1 \mathrm{HCl}$. Calcium, which inhibits the oxalate oxidase and therefore the enzymatic determination of oxalate, was bound with $2 \mathrm{ml}$ sodium EDTA $(8 \mathrm{~g} / \mathrm{l})$.

Sixty-three unfixed samples from autopsies were prepared in a similar manner and compared with forty fixed samples from autopsies. The diagnostic categories used for these samples from

\section{1) Enzymes}

Dispase (EC 3.4.24.4)

Papain (EC 3.4.22.2)

Pepsin (EC 3.4.23.1)

Pronase E (EC 3.4.24.4)

Trypsin (EC 3.4.21.4)

RNase (EC 3.1.27.5)

DNase (EC 3.1.21.1) 
autopsies could not be determined, because histological and scintigraphic data were not available for this group. The tissue of these unfixed samples pulverized in liquid nitrogen was not dehydrated by ethanol but lyophilized prior to further treatment.

The quantitative enzymatic test used for the determination of the oxalate content of the thyroid specimens is based on the oxidation of oxalate by oxalate oxidase, yielding carbon dioxide and hydrogen peroxide. Hydrogen peroxide is measured by means of an indamine dye. Maximal absorbance of the indamine dye lay at $592 \mathrm{~nm}$ (bandwidth $0.5 \mathrm{~nm}$ ) as determined with a Response spectrophotometer (Gilford, Giessen, Germany). Absorbance of samples was measured at this wavelength versus a blank. Thyrostatic agents, such as thiamazole, do not influence the measurements (23).

Reproducibility studies yielded an interassay coefficient of variation of $5 \%(n=11)$ and an intraassay coefficient of variation of $2 \%(n=10)$ when a lyophilized urine specimen was examined for oxalate (mean value, $24 \mathrm{mg} / \mathrm{l}$ ) with this test system. (Tissue specimens even from the same glands do not guarantee constant amounts of oxalate for reproducibility studies.)

To obtain accurate results, an internal standard (10 $\mu$ l of a 12.5 g/l oxalate solution) accompanied each sample. By measuring the oxalate content of the sample with and without the internal standard, a correction factor was determined separately for each individual sample. The mean correction factor was found to be $1.67 \pm 0.71(n=97$; range $0.70-3.27)$.

\section{Statistics}

Statistical methods applied in this study were Residual Analysis, One-Way Analysis of Variance, Multiple Regression Analysis, Least Significant Difference (LSD) (24) and the two-sample $t$ test for independent samples (25). The statistical packages SPSS, version 3.1 (University of Washington, Seattle, USA) and version 4.0 (University of Tübingen, Germany), were used.

Residual Analysis of a model including the seven diagnostic groups (cf. tab. 1) as a dummy independent variable, oxalate concentration (in $\mathrm{mg} / \mathrm{kg}$ dry substance) as the dependent variable, and age and sex as possible sources of variation suggested that the relationship is of exponential nature. Therefore, it was thought appropriate to transform the oxalate concentrations obtained into decadic logarithms for the statistical analyses.

\section{Resülts}

The mean oxalate content in fixed thyroid tissue from autopsies $(\mathrm{n}=40)$ was $880 \pm 1530 \mathrm{mg} / \mathrm{kg}$ dry substance and the mean oxalate concentration for unfixed thyroid tissue from autopsies was $1310 \pm 1770 \mathrm{mg} /$ $\mathrm{kg}$ dry substance $(\mathrm{n}=63)$. The difference between the unfixed and fixed samples was not statistically significant $(t=1.24 ; p>0.05)$. However, oxalate determination in the supernatants of the unfixed samples $(n=24)$ treated with protease and nuclease revealed varying amounts of oxalate (range approx. 100-600 $\mathrm{mg} / \mathrm{kg}$ dry substance) especially in those supernatants containing pepsin, papain and pronase E. This is probably due to the fact that these glands were not pretreated with $\mathrm{CaCl}_{2}$-ethanol. No oxalate was found in the supernatants of fixed glands $(n=19)$, so these supernatants could be discarded without oxalate loss.
For the unfixed thyroid glands, a loss of oxalate during the enzymatic treatment therefore has to be taken into account and may cast doubt upon the statistical non-significance between the two groups. The loss of oxalate was not pursued individually. The mean water content of the unfixed thyroid glands from the autopsies was $0.726 \pm 0.032 \mathrm{~g} / \mathrm{g}$ fresh substance $(\mathrm{n}=52)$ or $72.6 \%$.

Table 1 shows the mean oxalate concentration of the fixed thyroid tissue (surgical specimens) and the average age of the seven diagnostic groups. Figure 1 illustrates the difference in mean oxalate values between women and men.

Tab. 1. Mean oxalate concentration in thyroid tissue in $\mathrm{mg} / \mathrm{kg}$ dry substance in different histo-scintigraphical diagnostic groups: 1 = Diffuse colloid goitre, $2=$ Partially diffuse, partially nodular colloid goitre, $3=$ Nodular colloid goitre, $4=$ Goitre with multifocal functional autonomy, $5=$ Non-functioning adenoma, $6=$ Unifocal functional autonomy, 7 = Graves' disease; $\mathrm{n}=$ number of cases

\begin{tabular}{lrlrrl}
\hline $\begin{array}{l}\text { Diag- } \\
\text { nostic } \\
\text { group }\end{array}$ & $\mathrm{n}$ & $\begin{array}{l}\text { Mean age } \\
\text { (lower and } \\
\text { upper limits) } \\
\text { (years) }\end{array}$ & $\begin{array}{r}q \\
\mathrm{n}\end{array}$ & $\begin{array}{c}\hat{\mathrm{n}} \\
\mathrm{n}\end{array}$ & $\begin{array}{l}\text { Mean oxalate } \\
\text { concentration } \\
( \pm \text { standard } \\
\text { deviation) } \\
(\mathrm{mg} / \mathrm{kg})\end{array}$ \\
\hline 1 & 6 & $49(36-72)$ & 4 & 2 & $239 \pm 298$ \\
2 & 9 & $51(24-67)$ & 7 & 2 & $445 \pm 683$ \\
3 & 36 & $53(32-75)$ & 23 & 13 & $548 \pm 887$ \\
4 & 8 & $60(47-79)$ & 8 & 0 & $1007 \pm 1476$ \\
5 & 20 & $43(23-64)$ & 13 & 7 & $794 \pm 1323$ \\
6 & 10 & $53(34-75)$ & 7 & 3 & $654 \pm 696$ \\
7 & 8 & $32(21-53)$ & 6 & 2 & $57 \pm$ \\
\hline
\end{tabular}

One-way Analysis of Variance yielded $F=2.21$ and $p=0.048$ for the logarithms of the mean oxalate values of the seven diagnostic groups. This indicates that the differences between the diagnostic groups were barely statistically significant.

Multiple Regression Analysis revealed that the differences in oxalate concentration between the diagnostic groups were not only due to different pathological states, but also to differences in age and gender distribution as well as other possible sources of variation which were not taken into account.

The relationship between diagnostic groups and age did not change with age, i. e., there was no significant interaction (24) between the two variables $(p=0.32)$.

The LSD test was used to compare the logarithmic means of the oxalate concentrations of the seven diagnostic groups. It showed that diagnostic groups 3-6 were statistically different from group 7 (Graves' disease) at a significance level of 0.05 . 
Diffuse colloid goitre

Partially diffuse, partially nodular goitre

Nodular colloid goitre

Goitre with multifocal functional autonomy

Non-functioning adenoma

Unifocal functional autonomy

Graves' disease

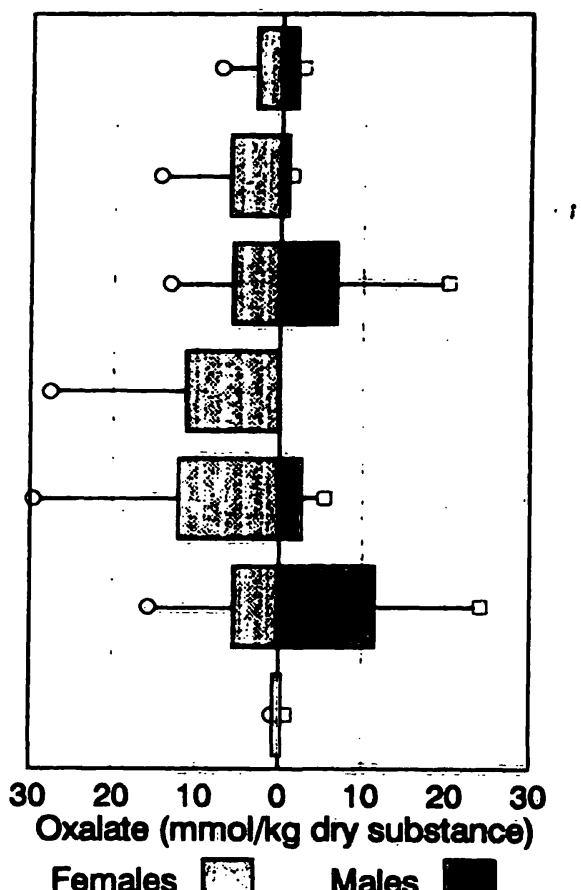

Females

Males

Fig. 1. Mean oxalate content ( $x$-axis) of the seven diagnostic groups used (y-axis) in women and men.

Four groups with increasing crystal population density were examined microscopically, using approximately five high-power fields of vision of haematoxylin and eosin stained slides (400-fold enlargement) under polarized light. It was shown that there is a direct proportional relationship between the number of birefringent calcium oxalate crystals and the amount of oxalate measured with the enzymatic assay (results not shown here). Particularly remarkable is the extremely small number of oxalate crystals found microscopically in thyroid glands of Graves' patients. This fact is in agreement with the low oxalate concentration found in Graves' thyroid glands (fig. 1).

\section{Discussion}

For the determination of oxalate in the thyroid gland, both fixed and unfixed tissue is suitable if the formaldehyde in the fixed samples is removed before further processing. In unfixed specimens not pretreated with $\mathrm{CaCl}_{2}$-ethanol, however, the oxalate determination is influenced by the loss of varying and measurable amounts of oxalate during the enzymatic treatment. As a general rule, unfixed thyroid glands should therefore also be pretreated with $\mathrm{CaCl}_{2}$-ethanol. Oxalate determination in each of the several supernatants produced during enzymatic digestion would complicate the oxalate determination. A possible inhibiting influence of traces of formaldehyde and other not identified inhibitors remaining in the tissue can be excluded by using an internal standard to determine a correction factor for each individual sample.
The technique of formaldehyde extraction with calcium chloride in absolute ethanol described above allows the omission of a time-consuming lyophilization procedure. As calcium chloride forms an insoluble complex of calcium with oxalate, oxalate is not lost during this procedure. The presence of calcium chloride also decreases the solubility of calcium oxalate by a 'common ion effect'. The solubility of calcium oxalate in aqueous solutions is also decreased by the presence of ethanol (1). The treatment with proteases is thought to be superior to ultrafiltration with subsequent acidification of the specimens (26). With the latter technique, only soluble oxalate is available for measurement, whereas insoluble calcium oxalate crystals are lost.

In blood, plasma, plasma ultrafiltrate and urine the measurement of oxalate is complicated by the fact that glyoxalate and especially ascorbate gradually convert to oxalate non-enzymatically at $\mathrm{pH}>4$ even at $-20^{\circ} \mathrm{C}(27-30)$. Kasidas \& Rose (27) prevented the in vitro generation of oxalate from $\dot{L}$-ascorbic acid by acidification and treatment with sodium nitrite. Such a gradual increase of oxalate in vitro cannot be excluded from our unfixed samples, but probably does not play a major role in our fixed tissue specimens, because formaldehyde forms addition products with $L$-ascorbic acid (31). 'In our autopsy specimens the mean oxalate content of the unfixed tissues was higher than for the tissues fixed with formaldehyde, but the difference was not statistically significant. The unknown losses of oxalate in the unfixed thyroid during the enzymatic treatment casts doubt on the significance of this finding. 
It was noted that in all diagnostic groups the standard deviation was quite large. This finding is probably not due to the methods employed but rather to the unequal distribution of oxalate crystals in the thyroid tissue (17). This was confirmed by our own examinations of histological slides of thyroid tissue under polarized light (results not shown here). As calcium is also not distributed equally in the thyroid gland (32), the present findings are not surprising. On the other hand, a high concentration of calcium does not necessarily correspond to a high concentration of oxalate, because calcium forms different salts in the thyroid. In functionally autonomous goitres, low calcium concentrations have previously been found (32), in contrast to the high oxalate concentrations found in the present study. In addition, the number of oxalate crystals found in the thyroid gland is also dependent on age, as already described by Richter in 1940 (33) and confirmed by Schaefer \& Rentzschke (34). The amount of calcium in the thyroid gland also increases with age (32).

The highest oxalate concentrations were found in goitres with functional autonomy, the lowest with Graves' disease. The latter finding is in agreement with the observations made by Richter et al. (8), who noted the oxalate crystals were absent in histological slides of thyroid glands with Graves' disease. Schaefer \& Rentzschke (34) demonstrated a decreasing number of crystals with an increasing degree of endocrine activity measured by the height of the follicular epithelium. The low oxalate concentration measured in hyperthyroid glands of the Graves' disease type must be a phenomenon specific to this immunogenic condition, particularly since the highest oxalate levels were found in non-immunogenic hyperthyroid states such as multifocal and unifocal functional autonomy.

Leukocytes involved in the production of antibodies contain high concentrations of ascorbate (35). A high oxalate content might therefore the expected in the thyroid glands with Graves' disease which are infiltrated by lymphocytes, but remarkably this was not the case. Maintenance of intracellular ascorbic acid is a priority for lymphocytes (36). Therefore one might suppose that lymphocytes infiltrating the thyroid act as scavengers of thyrọid ascorbate, because the ascorbate concentration in blood and tissue is lowered in thyrotoxicosis.

An important feature of immunological injuries also includes glycosaminoglycan depolymerization in the connective tissue (37). This could possibly diminish the nucleation process of oxalate formation and explain the low amounts of oxalate found in Graves' thyroids. However, the differences in oxalate concen- tration between the groups with hyperthyroid states, namely the high amount of oxalate found in the group with functional autonomy, could be due to age, as this group had the oldest patients. Since Gross (38) and Reith et al. (10) noted increased numbers of calcium oxalate crystals in de Quervain's thyroiditis, it is unlikely that the inflammatory process found in Graves' disease is a factor leading to the low oxalate concentration. It is also unlikely that the low oxalate content is a simple effect of enhanced blood flow in Graves' thyroids, because in nodules with functional autonomy blood flow is also enhanced. Nor is there a special preoperative treatment particularly for Graves' thyroid, which could influence oxalate concentration or determination. An effect of thiamazol on the determination was excluded by Weber-Hall (23).

Gross (38) and Reith et al. (10) also noted calcium oxalate deposits not only within the thyroid follicles, but also in the interstitium of thyroid glands with de Quervain's granulomatous thyroiditis. Since according to Sommers \& Meissner (39) an important feature of this disease is the rupturing of the basement membrane, the intrafollicular crystals could escape into the interstitium and cause granulomatous reactions. This would agree with the observations of Hasselbacher (40), who elicited tissue reactions by incubating rabbit fibroblast cultures with calcium oxalate crystals. A similar mechanism could play a role in functional autonomy, where degenerative changes also frequently occur. It is possible that oxalate deposits in degeneratively altered tissue are mobilized only with difficulty and hence accumulate with time. This is in agreement with the observation of Richter (33) and Schaefer et al. (34) that the number of birefringent oxalate crystals increases with age.

Whether or not there is a direct relationship between follicle size and the amount of oxalate is unkown. There is, however, a relationship between citric acid and follicle size, as demonstrated by Födisch et al. (41).

Oxalate gains pathognomonic significance in the human organism with excessive oxalate intake, with infection by oxalate-producing Aspergillus species, with diseases of the ileum leading to hyperoxaluria, with increased endogenous oxalate synthesis due to different enzyme defects, or pyridoxine or thiamine deficiency, and with chronic renal failure causing oxalate retention (1).

At present, the origin of calcium oxalate can only be hypothesized. Oxalic acid production may result from conversion of ascorbate to oxalate in situ. Oxalic acid production, however, also may be a physiological 
process in the thyroid gland: calcium oxalate crystals also appear in thyroid cell cultures if isolated porcine thyrocytes are spread in the culture medium (42). This could indicate that the thyroid gland is an important source of oxalate production in vivo as well. The mechanism of calcium oxalate crystal formation in the thyroid gland may be different from that of calcium oxalate nephrolithiasis, where a defective oxalate transport has been proposed (43). Hackett \& Khan (20) found calcium oxalate crystals in the thyroid gland in 4 out of 20 infants at autopsy. MacMahon et al. (17) found that crystals are already present in premature infants, whereas Reid et al. (19) could not confirm these results. MacMahon et al. (17) emphasize that the number of crystals increases with age. In addition, the occurrence of calcium oxalate is not confined to the human thyroid, but is also found in the thyroid glands of other mammalian species (44).

Since ascorbic acid has been suggested to play a physiological role in the regulation of iodination re- actions in the thyroid (45) and is involved in the synthesis of collagen (37) which plays a key role in the maintenance of structural integrity, calcium oxalate may be a metabolite of ascorbate metabolism. Calcium oxalate may also control the intracellular calcium metabolism of the thyroid cells. A controlling function at the level of enzymatic activity is also conceivable, as oxalate can inhibit several enzymes such as succinate dehydrogenase, alkaline and acid phosphatases and lactate dehydrogenase (46). Glycolic acid oxidase does not seem to be present in the human thyroid gland, however (19).

\section{Acknowledgement}

The authors wish to express their gratitude to Dr. E. Egner, Institut für Pathologie, Katharinenhospital, Stuttgart, Germany, for supplying the thyroid tissue, to Prof. P. Feigl, $\mathrm{PhD}$ University of Washington, Seattle, USA, and to Prof. Dr. $K$. Dietz, University of Tübingen, Germany, for their statistical advice, and to Mr. K. Wood for his linguistic assistance.

\section{References}

1. Hodgkinson, A. (1977) Oxalic Acid in Biology and Medicine, Academic Press, London.

2. Ludwig, G. (1963) Renal calculi associated with hyperoxaluria. Ann. N. Y. Acad. Sci. 104, 621-637.

3. Pyrah, L. N., Anderson, C. K., Hodgkinson, A. \& Zarembski, P. M. (1959) A case of oxalate nephrocalcinosis and hyperoxaluria. Brit. J. Urol. 31, 235-248.

4. Allison, M. J., Cook, H. M., Milne, D. B., Gallagher, J. S. \& Clayman, R. V. (1986) Oxalate degradation by gastrointestinal bacteria from humans. J. Nutr. 116, 455-460.

5. Yasue, T. (1969) Renal crystaline deposition and its pathogenesis. Acta Histochem. Cytochem. 2, 96-111.

6. Bennett, B. \& Rosenblum, C. (1961) Identification of calcium oxalate in the myocardium of patients with uremia. Lab. Invest. 10, 947-955.

7. Glynn, L. E. (1940) Crystalline bodies in the tunica media of a middle cerebral artery. J. Pathol. Bacteriol. 51, 445446.

8. Richter, M. N. \& McCarty, K. S. (1954) Anisotropic crystals in the human thyroid gland. Am. J. Pathol. 30, 545553.

9. Chaplin, A. J. (1974) Some observations in the demonstration of calcium oxalate in tissue sections. Stain Technology 49, $165-173$.

10. Reith, H. B., Mackowski, M. \& Kozuschek, W. (1989) Oxalose and granulomatöse Thyreoiditis. Krankenhausarzt (Braun, Karlsruhe) 62, 316-318.

11. Boquist, L. B., Lindqvist, B., Östberg, Y. \& Steen, L. (1973) Primary oxalosis. Am. J. Med. 54, 673-681.

12. Pons, C. A. \& Cluster, R. P. (1946) Acute ethylene glycol cases. Am. J. Med. Sci. 211, 544-552.

13. Cogan, D. G., Kuwabara, T., Silbert, J., Kern, H., MacMurray, V. \& Hurlbut, C. (1958) Calcium oxalate and calcium phosphate crystals in detached retinas. Arch. Ophthalmol. 60, 366-371.

14. Johnson, F. B. \& Pani, K. (1962) Histochemical identification of calcium oxalate. Arch. Pathol. 74, 347-351.

15. Peiffer, J., Danner, E. \& Schmidt, P. F. (1984) Oxalate induced encephalitic reactions to polyol-containing infusions during intensive care. Clin. Neuropathol. 3, 76-87.
16. Gardner, G. L. (1975) Nucleation and crystal growth of calcium oxalate trihydrate. J. Cryst. Growth 30, 158-168.

17. MacMahon, H. E., Lee, H. Y. \& Rivelis, C. F. (1968) Birefingent crystals in human thyroid. Acta Endocrinol. 58, $172-176$

18. Krause, W., cited by Kühne, W. (1868) Lehrbuch der Physiologischen Chemie, p. 415, Engelmann, Leipzig.

19. Reid, J. D., Choi, C.-H. \& Oldroyd, N. O. (1987) Calcium oxalate crystals in the thyroid. Their identification, prevalence, origin and possible significance. Am. J. Clin. Pathol. $87,443-454$.

20. Hackett, R. L. \& Khan, S. R. (1988) Presence of calcium oxalate crystals in the mammalian thyroid gland. Scanning Microsc. 2, 241-246.

21. Andrews, J. C. \& Viser, E. T. (1951) The oxalic acid content of some common foods. Food Res. 16, 306-312.

22. Smyth, D. G. (1967) Techniques in enzyme hydrolysis. In: Methods in Enzymology, Vol. IX: Enzyme structure (Hirs, C. H. W., ed.) pp. 214-231, Academic Press, New YorkLondon.

23. Weber-Hall, R. (1990) Oxalsäurekonzentration in der menschlichen Schilddrüse, Doctoral Dissertation, University of Tübingen.

24. Kleinbaum, D. G., Kupper, L. L. \& Muller, K. E. (1987) Applied regression analysis and other multivariable methods, 2nd edn. pp. 165-174 and 361 - 365, PWS-Kent Publishing Company, Boston.

25. Rosner, B. (1986) Fundamentals of Biostatistics, 2nd edn. pp. 246-251, Duxbury Press, Boston.

26. Bergmeyer, H. U. (1984) Methods of Enzymatic Analysis, 3rd edn., Vol. VIII, pp. 649-656, Verlag Chemie, Weinheim/Bergstraße.

27. Kasidas, G. P. \& Rose, G. A. (1986) Measurement of plasma oxalate in healthy subjects and in patients with chronic renal failure using immobilised oxalate oxidase. Clin. Chim. Acta 154, 49-58.

28. Costello, J. \& Landwehr, D. M. (1988) Determination of oxalate concentration in blood. Clin. Chem. 34, 15401544. 
29. Berckmans, R. J. \& Boer, P. (1988) An inexpensive method for sensitive enzymatic determination of oxalate in urine and plasma. Clin. Chem. 34, 1451-1455.

30. Wilson, D. M. \& Liedtke, R. R. (1991) Modified enzymebased colorimetric assay of urinary and plasma oxalate with improved sensitivity and no ascorbate interference: Reference values and sample handling procedures. Clin. Chem. 37, 1229-1235.

31. Tresl, L., Cho, Y. B., DiMaria, P., Kim, S., Lotlikar, P. D. \& Paik, W. K. (1988) Studies on the reaction of formaldehyde with naturally occurring thiol compounds and ascorbic acid. Archives of Pharmacal Research (Seoul) 11, 114-121.

32. Wahl, R., Hellstern, M. J. \& Kallee, E. (1985) Calcium im Kolloid und Gesamtgewebe der menschlichen Schilddrüse. Aktuelle Endokrinologie und Stoffwechsel (Thieme, Stuttgart) $6,7-10$.

33. Richter, M. N. (1940) Anisotropic crystalloids in the human thyroid gland. Am. J. Pathol. 16, 654-655.

34. Schaefer, H.-E. \& Rentzschke, R.-D. (1975) Das alters- und funktionsabhängige Vorkommen von Calciumoxalatkristallen im Schilddrüsenkolloid. Licht- und elektronenmikroskopische Untersuchungen. Verh. Dtsch. Ges. Pathol. $59,410-414$.

35. Lewin, S. (1976) Vitamin C: Its Molecular Biology and Medical Potential, pp. 81-82, Academic Press, LondonNew York-San Francisco.

36. Jacob, R. A., Pianalto, F. S. \& Agee, R. E. (1992) Cellular ascorbate depletion in healthy men. J. Nutr. 122, $1111-$ 1118.

37. Kohn, L. D. (1986) Connective Tissue. In: Werner's The Thyroid, 5th edn. (Ingbar, S. H. \& Braverman, L. E., eds.) pp. 816-839, Lippincott Company, Philadelphia.
38. Gross, S. (1955) Granulomatous thyroiditis with anisotropic crystalline material. Arch. Pathol. Lab. Med. 59, $412-418$.

39. Sommers, S. C. \& Meissner, W. A. (1954) Basement membrane changes in chronic thyroiditis and other diseases. Am J. Clin. Pathol. 24, 434-440.

40. Hasselbacher, P. (1982) Stimulation of synovial fibroblasts by calcium oxalate and monosodium urate monohydrate. A mechanism of connective tissue degradation in oxalosis and gout. J. Lab. Clin. Med. 100, 977-985.

41. Födisch, J. H., Riccabona, G., Marberger, E. \& Marberger, H. (1966) Der Citronensäuregehalt in Strumen und seine Abhängigkeit von Morphologie und Funktion des Organs. Klin. Wochenschr. 44, 1066-1071.

42. Wahl, R. W. (1991) Morphologische und biochemische Untersuchungen an der Schilddrüsenzellkultur. In: Theorie und Forschung, Bd. 161, Biochemie, Bd. 2, p. 152, Roderer, Regensburg.

43. Menon, M. \& Koul, H. (1992) Clinical Review 32 - Calcium Oxalate Nephrolithiasis. J. Clin. Endocr. Metab. 74, 703-707.

44. Reid, J. D. (1991) Calcium oxalate in mammalian thyroids: A re-evaluation. J. Comp. Pathol. 105, 109-115.

45. Suzuki, M., Nagashima, M. \& Yamamoto, K. (1961) Studies on the mechanism of iodination by the thyroid gland: Iodide-activating enzyme and an intracellular inhibitor of iodination. Gen. Comp. Endocrinol. 1, 103-116.

46. Tietz, N. W. (1986) Textbook of Clinical Chemistry, 3rd edn., p. 486, Saunders, Philadelphia.

Priv. Doz. Dr. med. Richard Wahl Medizinische Klinik und Poliklinik, Abt. IV

Eberhard-Karls-Universität D-72076 Tübingen Germany 
I 